\title{
Cholesterol targeting alters lipid raft composition and cell survival in prostate cancer cells and xenografts
}

\author{
Liyan Zhuang,,,$^{1,2}$ Jayoung Kim,,1,2 Rosalyn M. Adam,1,2 Keith R. Solomon,1,3,4 \\ and Michael R. Freeman ${ }^{1,2}$ \\ 1The Urological Diseases Research Center, Department of Urology, Children's Hospital Boston, Boston, Massachusetts, USA. \\ 2Department of Surgery, and 'Department of Orthopaedic Surgery, Harvard Medical School, Boston, Massachusetts, USA. \\ ${ }^{4}$ Department of Orthopaedic Surgery, Children's Hospital Boston, Boston, Massachusetts, USA.
}

\begin{abstract}
Lipid rafts are cholesterol- and sphingolipid-enriched microdomains in cell membranes that regulate phosphorylation cascades originating from membrane-bound proteins. In this study, we tested whether alteration of the cholesterol content of lipid rafts in prostate cancer (PCa) cell membranes affects cell survival mechanisms in vitro and in vivo. Simvastatin, a cholesterol synthesis inhibitor, lowered raft cholesterol content, inhibited Akt1 serine-threonine kinase (protein kinase $B \alpha$ )/protein kinase $B(A k t / P K B)$ pathway signaling, and induced apoptosis in caveolin- and PTEN-negative LNCaP PCa cells. Replenishing cell membranes with cholesterol reversed these inhibitory and apoptotic effects. Cholesterol also potentiated Akt activation in normal prostate epithelial cells, which were resistant to the apoptotic effects of simvastatin. Elevation of circulating cholesterol in SCID mice increased the cholesterol content and the extent of protein tyrosine phosphorylation in lipid rafts isolated from $\mathrm{LNCaP} / \mathrm{sHB}$ xenograft tumors. Cholesterol elevation also promoted tumor growth, increased phosphorylation of Akt, and reduced apoptosis in the xenografts. Our results implicate membrane cholesterol in Akt signaling in both normal and malignant cells and provide evidence that PCa cells can become dependent on a cholesterol-regulated Akt pathway for cell survival.
\end{abstract}

\section{Introduction}

Certain cues for cell growth, survival, and other physiological processes are transmitted through discrete regions in the plasma membrane known as lipid rafts $(1,2)$. Lipid raft microdomains are characterized by light buoyant density, insolubility in cold nonionic detergents, and relatively high levels of glycosphingolipids and cholesterol, which contribute to their detergent-resistant, liquid-ordered structure. Caveolae ("little caves") are a specialized type of raft characterized by 50 - to $100-\mathrm{nm}$ invaginations in the plasma membrane (2). The distinctive, pitted cytomorphology exhibited by caveolar rafts arises from the structural contribution of membrane proteins of the caveolin family $(3,4)$. Caveolins regulate a variety of signal transduction processes by direct protein-protein interaction and by facilitating molecular sequestration within caveolae (5). Lipid rafts that do not contain caveolins, and which consequently do not form invaginated membrane structures, are also isolated from cells using identical approaches to those used for caveolar rafts. These "flat" rafts resemble caveolae biochemically in their cholesterol and sphingolipid content and in the general classes of proteins that associate with them, either transiently or in a stable manner (1). Invaginated and flat rafts are enriched in certain signaling proteins, including Src-family kinases, hetero-

Nonstandard abbreviations used: Akt, Akt1 serine-threonine kinase (protein kinase $\mathrm{B} \alpha$ ); $\mathrm{C}+\mathrm{M}$, cytosolic plus nonraft membrane (fraction); Cav-1, caveolin-1; $\mathrm{G}_{\mathrm{i} \alpha 2}$, G protein $\alpha$ inhibitory subunit; GSK, glycogen synthase kinase; Hh, Hedgehog; OCG, octylglucoside; $\mathrm{pAb}$, polyclonal antibody; PCa, prostate cancer; $\mathrm{PKB}$, protein kinase B; PrEC, normal prostate epithelial cell; Ptc, Patched; PTEN, phosphatase and tensin homolog on chromosome 10; TBS, Tris-buffered saline.

Conflict of interest: The authors have declared that no conflict of interest exists.

Citation for this article: J. Clin. Invest. 115:959-968 (2005)

doi:10.1172/JCI200519935 trimeric $\mathrm{G}$ protein subunits, and receptor tyrosine kinases. Lipid rafts have been shown to regulate signal transduction by activating or suppressing phosphorylation cascades (6).

The potential role of lipid rafts in the progression of solid tumors is poorly understood. However, the role of caveolin-1 (Cav-1) in signaling mechanisms relevant to cancer has been extensively studied. Cav-1 has been identified as a marker of aggressive disease in prostate, pancreatic, and esophageal carcinoma (7-10). In model systems, Cav-1 was demonstrated to promote progression to the metastatic phenotype (11). Cav-1 has also been shown to colocalize transiently with androgen and estrogen receptors at the plasma membrane and may be a direct mediator of hormone action $(12,13)$, suggesting that growth and survival signals might be routed through caveolar rafts in hormone-responsive cancers. Some mediators of tumor cell growth, such as the Akt1 serine-threonine kinase (protein kinase $\mathrm{B} \alpha$ )/protein kinase $\mathrm{B}(\mathrm{Akt} / \mathrm{PKB})$, may be positively regulated by Cav-1 (14). On the other hand, Cav-1 is capable of suppressing the activity of a number of signaling proteins activated in aggressive cancers, including Src-like kinases (15) and certain receptor tyrosine kinases (16). Similarly a cav-1-/- genotype accelerated mammary dysplasia in tumor-prone transgenic mice (17), suggesting a moderate tumor suppressor-like activity for the protein. Thus, caveolins may contribute either positively or negatively to tumor progression under different circumstances. Collectively, the caveolin literature points to the likelihood that tumor progression is mediated, in part, by pathways that use lipid rafts as signaling platforms.

Prostate cancer (PCa) incidence has been linked to a Western diet, which includes high levels of red meat, saturated fat, and dairy products (18). The molecular basis for these epidemiological relationships is obscure; however, an unknown constituent of 

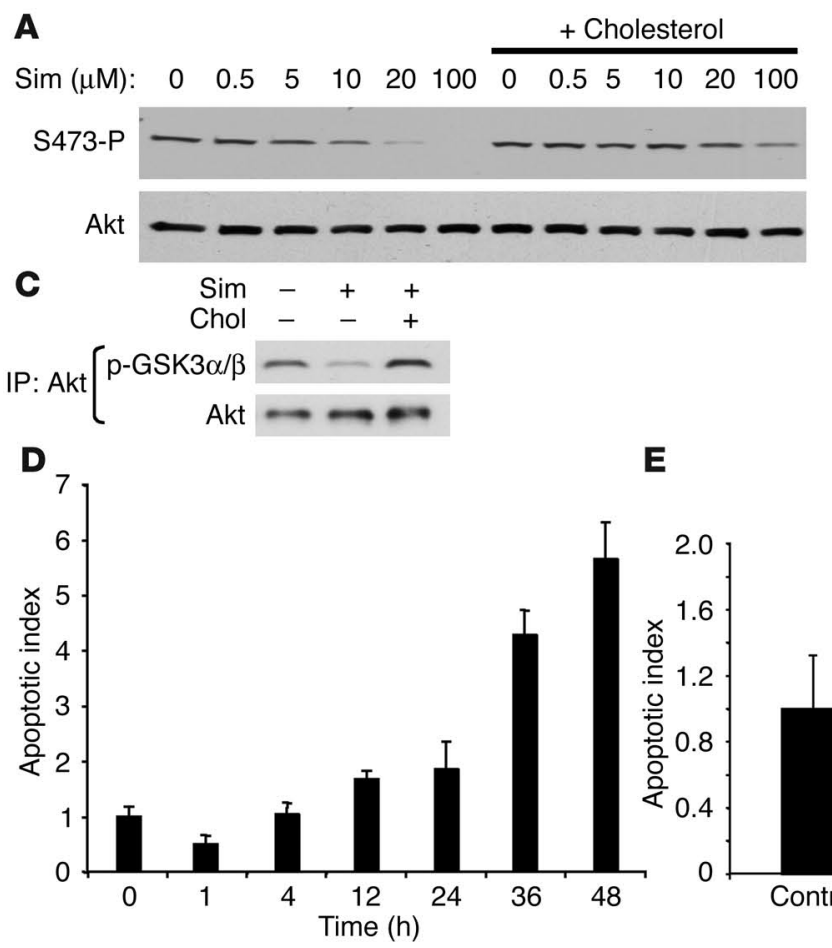

$\mathbf{E}$

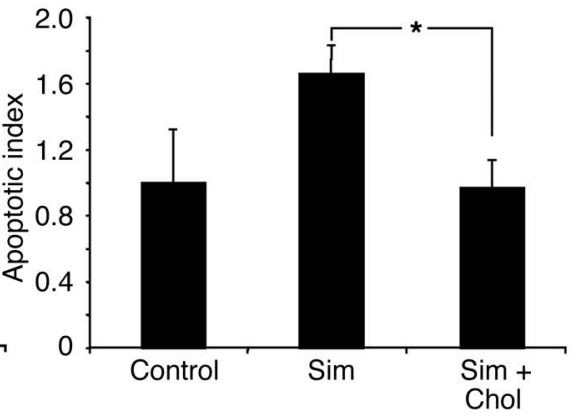

B

P: Akt

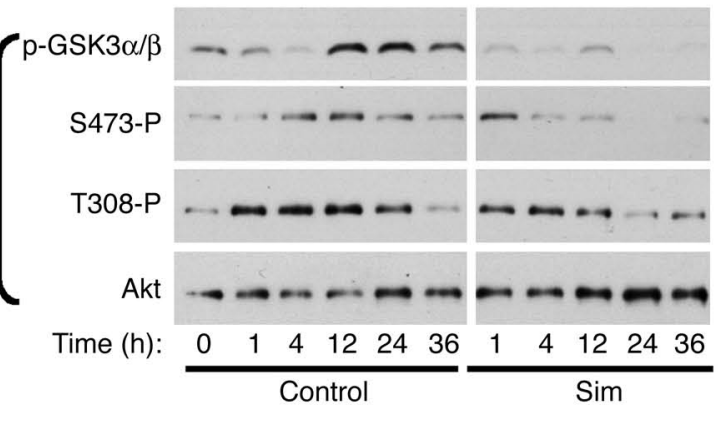

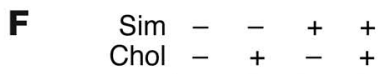
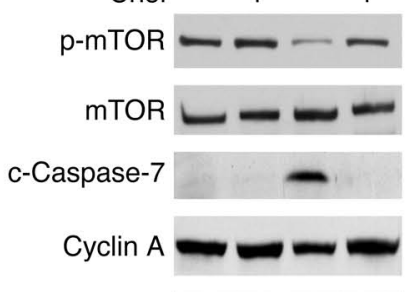

$\beta$-Actin $-\ldots$

\section{Figure 1}

Simvastatin treatment downregulates Akt phosphorylation and Akt kinase activity and induces apoptosis in LNCaP cells. (A) Cells were incubated with varying doses of simvastatin (sim) in the absence or presence of cholesterol complexes for 16 hours. Whole-cell lysates were resolved by SDS-PAGE and immunoblotted with antibodies to total Akt or S473-phosphorylated Akt (S473-P). (B) LNCaP cells were incubated in the presence of $20 \mu \mathrm{M}$ simvastatin or vehicle (control) in serum-free medium at $37^{\circ} \mathrm{C}$ for the indicated times, after which lysates were collected for Western blot and in vitro kinase assay. A GSK3 fusion protein was used as Akt substrate after immunoprecipitation with anti-Akt antibody. Kinase assay eluates were blotted with antibodies to total Akt, phospho-GSK3 $\alpha / \beta$ (p-GSK3 $\alpha / \beta)$, T308-P Akt, and S473-P Akt. (C) Cells in serum-free medium were treated with $20 \mu \mathrm{M}$ simvastatin in the absence or presence of cholesterol (chol) complexes at $37^{\circ} \mathrm{C}$ for 12 hours, after which lysates were collected and kinase assay was performed as in B. (D) LNCaP cells were treated for varying times with $20 \mu \mathrm{M}$ simvastatin. Apoptosis was determined by DNA fragmentation. The means \pm SD of triplicate determinations are shown. (E) LNCaP cells were treated with $20 \mu \mathrm{M}$ simvastatin with or without cholesterol complexes for 12 hours followed by DNA fragmentation analysis $\left({ }^{*} P<0.05\right)$. (F) LNCaP cells were incubated with $20 \mu \mathrm{M}$ simvastatin with or without cholesterol complexes for 12 hours, after which lysates were collected for immunoblot with the indicated antibodies. c-Caspase-7, cleaved caspase-7.

dietary fat has been suggested to be a potential contributor to a progression mechanism $(19,20)$. Cholesterol, a neutral lipid that is a prominent component of the Western diet, contributes to the unique biophysical properties of the lipid raft microdomain and is mechanistically important for signal transduction by raft proteins. Disruption of lipid rafts by dispersion or extraction of membrane cholesterol results in inhibition of raft-dependent signaling events (21-23). Cholesterol is synthesized by tumor cells but also enters cells from the circulation by LDL receptor-mediated endocytosis (24). Feedback regulation of cholesterol absorption and synthesis is lost in prostate and other types of cancer cells, resulting in upregulation of the cholesterol synthesis (mevalonate) pathway and increases in LDL receptor expression $(25,26)$.

The Akt/PKB serine-threonine kinase family (Akt $1-3 / \mathrm{PKB} \alpha, \beta, \gamma)$ is a critical node for cell survival signal transduction in human cancer (27). This is partly due to frequent inactivation in solid tumors of the phosphatase and tensin homolog on chromosome 10 (PTEN), an upstream inhibitor of $\operatorname{Akt}(28,29)$. Our group recently reported that cell survival and Akt phosphorylation are mediated by a cholesteroldependent mechanism in LNCaP PCa cells, which do not express caveolins and are PTEN-negative $(23,30)$. These findings suggest that alterations in the cholesterol content of tumor cell rafts, in isolation from caveolin expression per se, may be a critical determinant of tumor progression. Consistent with this possibility, some studies have linked hyperlipidemia to increases in cancer risk (31) and longterm cholesterol-lowering therapy to lower cancer risk $(32,33)$.

These potential links between cholesterol and raft-dependent signal transduction mechanisms in cancer cell membranes suggest several experimental possibilities: (a) Can signaling mechanisms regulating PCa cell survival be altered by pharmacologic targeting of membrane cholesterol? (b) Can the composition of flat (caveolin-negative) lipid rafts be altered in tumor cells by inhibition of endogenous cholesterol synthesis? (c) Are lipid rafts altered in tumors in vivo by hypercholesterolemia? (d) Does alteration of raft composition coincide with changes in tumor aggressiveness and/or raft-dependent signaling functions? In this study, we address these questions using the LNCaP human PCa model.

\section{Results}

Simvastatin affects Akt signaling, cell survival, and cholesterol levels in lipid rafts. In an initial series of experiments, we asked whether inhibition of endogenous cholesterol synthesis, rather than dis- 
A

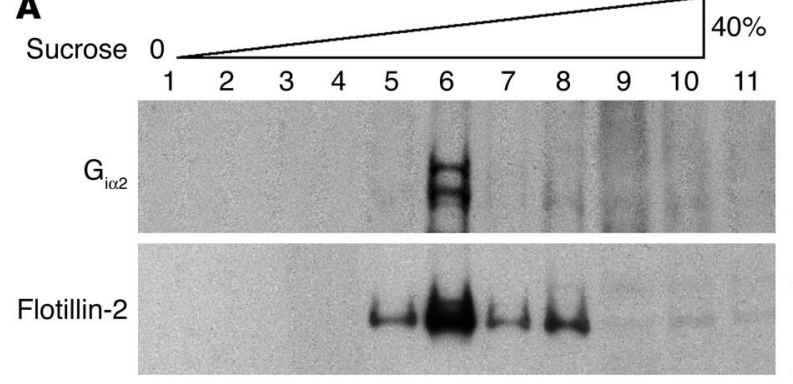

B Lipid raft (light buoyant density)

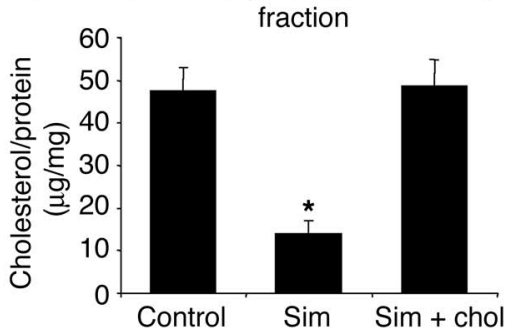

C

EGFR

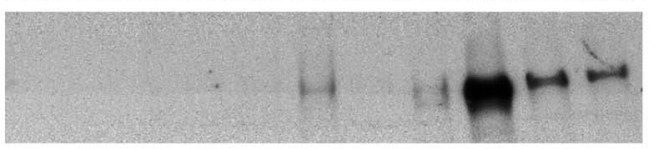

Control

Simvastatin
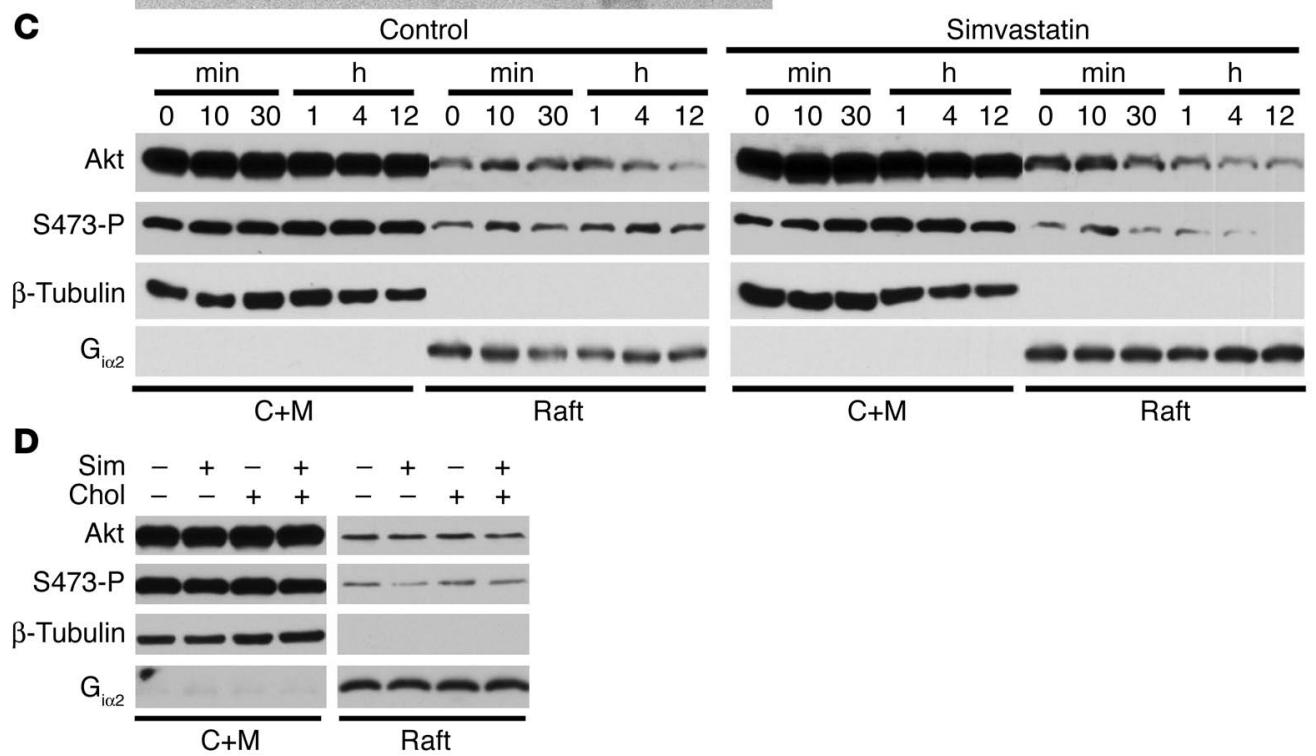

Raft

$\mathrm{C}+\mathrm{M}$

Raft

Figure 2

Simvastatin treatment reduces the cholesterol content of lipid rafts of LNCaP cells and inhibits Akt phosphorylation in rafts. (A) Immunoblot results obtained following fractionation of Triton X-100-insoluble material by sucrose gradient ultracentrifugation. This panel demonstrates how lipid raft fractions used for the cholesterol determinations shown in $\mathbf{B}$ were obtained. Flotation fractions demonstrating enrichment in the raft markers $\mathrm{G}_{\mathrm{i} \alpha 2}$ and flotillin-2 (i.e., fraction 6 in this example) were designated as raft fractions. (B) Cells were incubated in serum-free medium in the absence (control) or presence of $10 \mu \mathrm{M}$ simvastatin overnight at $37^{\circ} \mathrm{C}$. After the drug treatment, 1 group was incubated with cholesterol complexes (sim $\left.+\mathrm{chol}\right)$ at $37^{\circ} \mathrm{C}$ for 1 hour. The cholesterol/protein ratio was determined in lipid raft fractions prepared as shown in $\mathbf{A}$ and under the conditions described in the text. Values shown are means \pm SD of triplicate determinations $\left({ }^{*} P<0.01\right)$. (C) Cells were incubated in the presence of $20 \mu \mathrm{M}$ simvastatin or vehicle in serum-free medium at $37^{\circ} \mathrm{C}$ for the indicated times. C+M and raft fractions were isolated by successive detergent extraction, resolved by SDS-PAGE, transferred to nitrocellulose membranes, and immunoblotted with the indicated antibodies. (D) Cells were treated with $20 \mu \mathrm{M}$ simvastatin with or without cholesterol complexes for 4 hours, followed by raft extraction and analysis as in $\mathbf{C}$.

persion of cholesterol from rafts by an exogenous agent (23), alters Akt signaling and apoptosis rates in LNCaP cells. To address this question we used simvastatin, an FDA-approved cholesterol-lowering drug. Simvastatin, like other statins (34), is an inhibitor of the enzyme HMG-CoA reductase, which catalyzes the rate-limiting step (HMG-CoA to mevalonate) in cholesterol biosynthesis. Statin drug-induced apoptosis in PCa cells has been reported (35), but the mechanism of this effect is unknown. Treatment of LNCaP cells with simvastatin for 16 hours decreased phosphorylation of Akt in a dose-dependent manner (Figure 1A), with substantial inhibition evident at $20 \mu \mathrm{M}$ simvastatin. Serumfree conditions were used because serum contains significant amounts of cholesterol. Simvastatin-induced inhibition of Akt phosphorylation was reversible by replenishment of cellular cholesterol levels; this is consistent with reformation of raft microdomains. Simvastatin also elicited dose-dependent effects on apoptosis in LNCaP cells (not shown). The $20-\mu \mathrm{M}$ simvastatin dose was used in subsequent experiments.

Consistent with published data that serum withdrawal stimulates Akt activity in LNCaP cells (36), we observed a time-dependent increase in Akt activity and phosphorylation at the 2 principal regulatory sites (T308 and S473) when cells were placed in serum-free conditions (Figure 1B). Simvastatin treatment under serum-free conditions resulted in a relative reduction in Akt kinase activity and a time-dependent decrease in phosphorylation at both regulatory sites (T308 and S473; Figure 1B). To test whether the effect of simvastatin on Akt activity was cholesterol-dependent, cholesterol complexes were added to cells simultaneously 


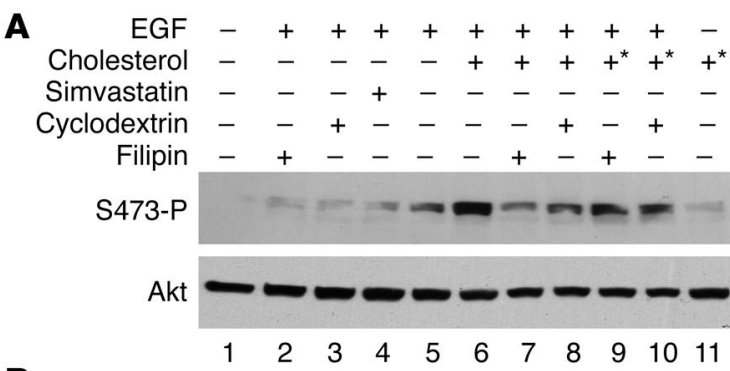

B

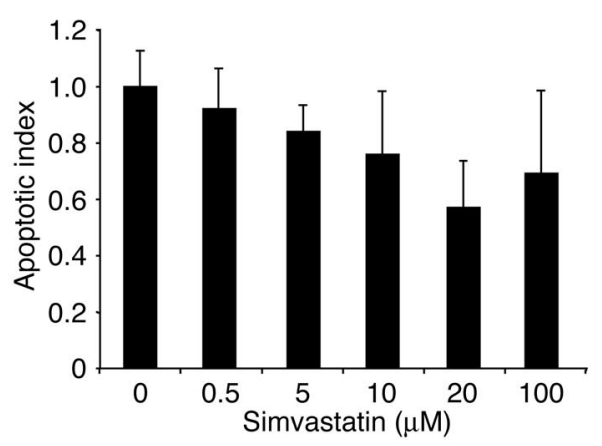

with simvastatin. Cholesterol repletion reversed the inhibition of Akt by simvastatin (Figure 1C), suggesting that this effect was mediated by a reduction in membrane cholesterol.

Consistent with the observation that constitutive PI3K/Akt pathway signaling is required for survival of LNCaP cells (37), simvastatin induced a time-dependent increase in apoptosis (Figure 1D). This effect was preceded by reductions in Akt activity as assessed in whole-cell lysates (Figure 1, A and B). To determine whether the apoptotic effect of simvastatin was cholesterol-dependent, cholesterol complexes were added to cells simultaneously with simvastatin, and apoptotic rates were measured. Following cholesterol repletion of cell membranes, apoptosis was inhibited (Figure 1E). Consistent with the simvastatin-induced inhibition of Akt phosphorylation and kinase activity (Figure 1, A-C), phosphorylation of the Akt effector mammalian target of rapamycin (mTOR) was also inhibited by simvastatin (Figure 1F). Phosphorylation of mTOR was restored to basal levels following cholesterol replacement (Figure 1F). We also determined the effect of simvastatin on caspase-7 and cyclin A. Levels of cleaved caspase- 7 increased markedly in response to simvastatin treatment for 12 hours, but not following cholesterol repletion (Figure 1F). We also observed a modest decrease in cyclin A levels with simvastatin treatment; these returned to the basal

\section{Figure 4}

High levels of serum cholesterol increase tumor aggressiveness. (A) Serum cholesterol levels in venous blood after stable elevation using dietary modification for 4 weeks. Values are means \pm SD of determinations from 5 animals $(P<0.001)$. (B) Subcutaneous xenograft tumors were created by subcutaneous injection of LNCaP/sHB cells after stable cholesterol elevation was demonstrated. The tumor take was significantly different between normal and high-cholesterol groups $(P<0.0001)$. (C) Mice were sacrificed 6 weeks after tumor cell injection. Four representative xenograft tumors from each group are shown. (D) Volume measurements were made at 5 weeks and 6 weeks after tumor cell injection. Median tumor volumes (horizontal lines) for the normal group were $0.077 \mathrm{~cm}^{3}$ (5 weeks) and $0.099 \mathrm{~cm}^{3}$ (6 weeks); median tumor volumes for the hypercholesteremic group were $0.135 \mathrm{~cm}^{3}$ (5 weeks) and $0.141 \mathrm{~cm}^{3}$ (6 weeks) $\left({ }^{\star} P<0.01 ;{ }^{* \star} P<0.005\right)$.

\section{Figure 3}

Cholesterol depletion inhibits Akt phosphorylation but does not induce apoptosis in PrECs. (A) Immunodetection of Akt in cell lysates following treatments. PrECs were treated with $20 \mathrm{ng} / \mathrm{ml} \mathrm{EGF,} \mathrm{in} \mathrm{the} \mathrm{presence}$ or absence of cholesterol complexes, under the following conditions: 1 hour of pretreatment with $2 \mu \mathrm{g} / \mathrm{ml}$ filipin (lane 2), 1 hour of pretreatment with $20 \mathrm{mM}$ cyclodextrin (lane 3), 16 hours of pretreatment with $20 \mu \mathrm{M}$ simvastatin (lane 4), 1 hour of pretreatment with vehicle (lane 5). After 1 hour of cholesterol pretreatment (lane 6), some groups were incubated with $2 \mu \mathrm{g} / \mathrm{ml}$ filipin (lane 7 ) or $20 \mathrm{mM}$ cyclodextrin (lane 8). Other groups treated identically to conditions in lanes 7 and 8 were repleted (asterisk) with cholesterol for 1 hour (lanes 9 and 10). (B) PrECs were treated with varying concentrations of simvastatin or vehicle for 24 hours, and the extent of apoptosis was determined by DNA fragmentation. Values shown are means \pm SD of triplicate determinations.

level with re-addition of cholesterol (Figure 1F). Taken together, these data suggest that the apoptotic effect of simvastatin results from inhibition of Akt pathway signaling.

To determine whether simvastatin treatment alters the cholesterol composition of lipid raft microdomains, LNCaP cells were treated with simvastatin for 16 hours, with and without cholesterol repletion, and lipid raft fractions were isolated by sucrose gradient ultracentrifugation. Raft fractions were identified by immunoblot of gradient fractions with antibodies against the raft markers $G$ protein $\alpha$ inhibitory subunit $\left(\mathrm{G}_{\mathrm{i} \alpha 2}\right)$ and flotillin-2 (Figure $\left.2 \mathrm{~A}\right)$. In the example shown, flotillin-2 was present in fractions 5-8, while $\mathrm{G}_{\mathrm{i} \alpha 2}$ was largely restricted to fraction 6 ; this indicates that lipid raft components were located within fractions 5-8 (primarily fraction 6 in the figure). Consistent with this interpretation, the EGFR was found predominantly outside the raft compartment, a result previously reported for LNCaP cells (23). Using this methodology, we isolated verified raft fractions from cells treated with vehicle, simvastatin, and simvastatin plus cholesterol. Cholesterol content was subsequently measured after extraction of lipids with chloroform and methanol. In comparison with control cells, cholesterol content (normalized to protein) in rafts was significantly decreased by simvastatin treatment, while repletion of membrane cholesterol restored

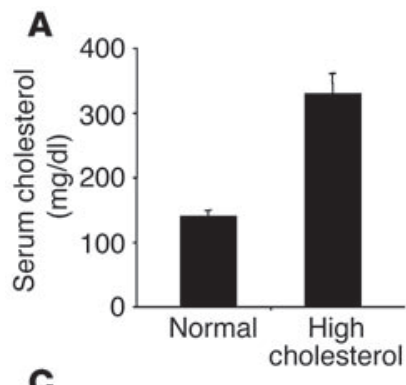

B
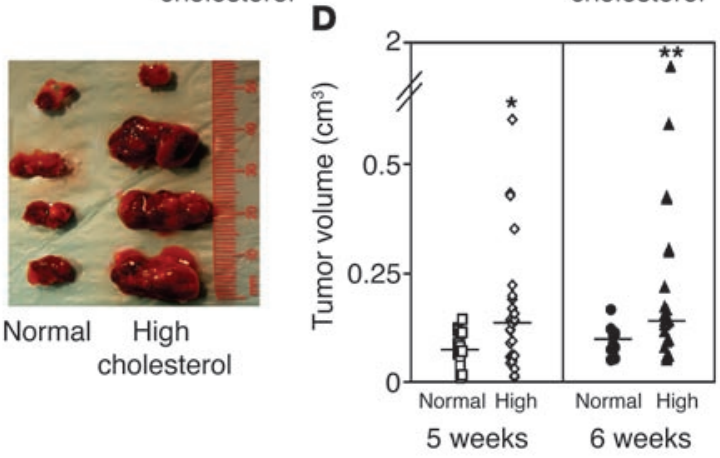

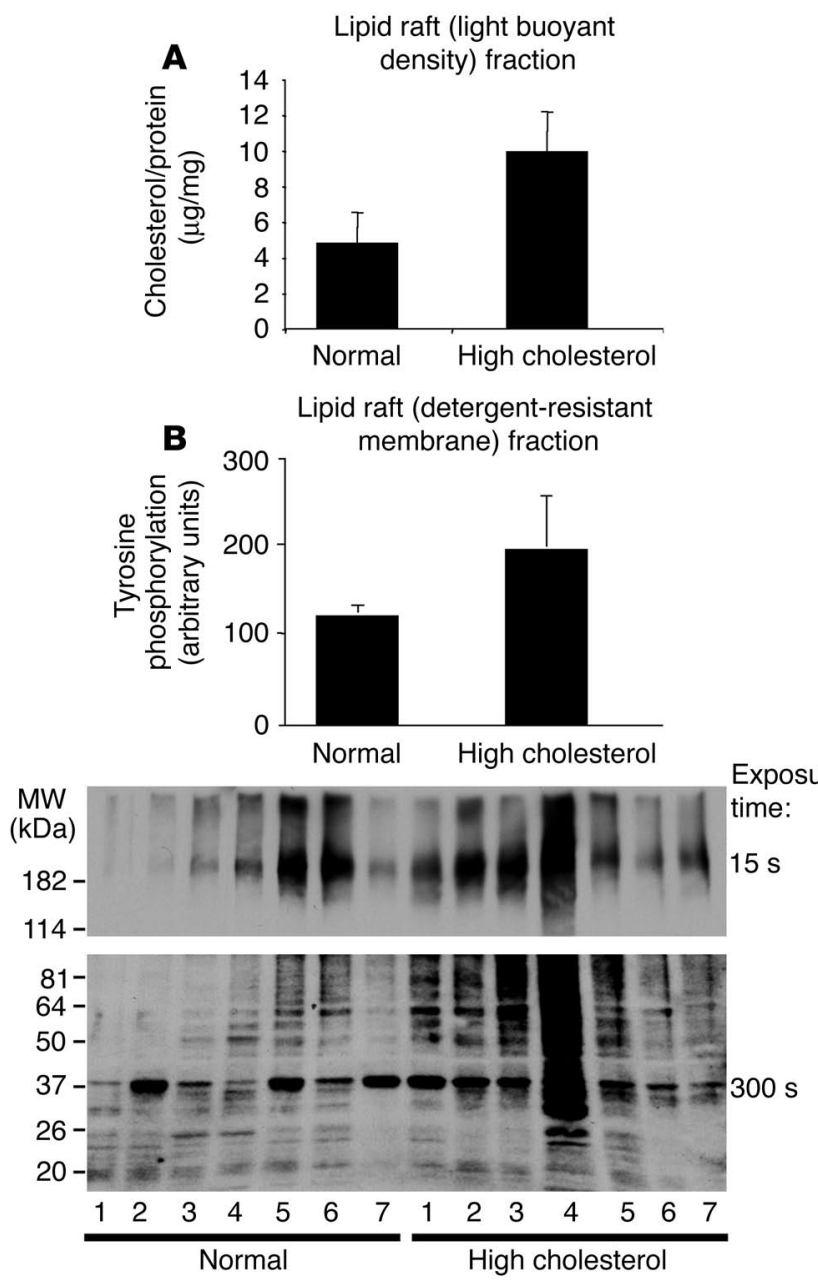

raft cholesterol to normal levels (Figure 2B). This result indicates that cholesterol content of membrane rafts is significantly reduced by pharmacologic inhibition of endogenous cholesterol synthesis.

In view of the marked effect of simvastatin treatment on Akt phosphorylation and activity in whole-cell lysates (Figure 1) as well as on raft composition (Figure 2B), we determined the effect of simvastatin on raft-localized Akt. Raft and cytosolic plus nonraft membrane $(\mathrm{C}+\mathrm{M})$ fractions were isolated from $\mathrm{LNCaP}$ cells treated with simvastatin for different times. In these preparations, the raft fraction consists of detergent-resistant membranes that are insoluble in cold Triton X-100, from which cytoskeletal and nuclear structures are removed by pelleting of the insoluble material. Raft material is solubilized in buffer containing octylglucoside (OCG) (38). These preparations are essentially identical to raft preparations obtained by flotation of Triton X-100-insoluble material in sucrose gradients (39).

Akt was present in both $\mathrm{C}+\mathrm{M}$ and raft fractions of control and simvastatin-treated cells but was more abundant in the $\mathrm{C}+\mathrm{M}$ fraction (Figure 2C). Akt localization was not detectably altered with simvastatin treatment, nor was Akt phosphorylation altered in the $\mathrm{C}+\mathrm{M}$ fraction (Figure 2C). In contrast, Akt phosphorylation was decreased in rafts of simvastatin-treated cells by 4 hours and remained suppressed for the duration of the experiment. No such decrease was evident in cells under control conditions (Figure 2C). Replacement of membrane cholesterol partially restored Akt phosphorylation

\section{Figure 5}

Elevated cholesterol and protein tyrosine phosphorylation in lipid rafts isolated from xenograft tumors exposed to high circulating cholesterol. (A) Cholesterol level in lipid rafts isolated from $\mathrm{LNCaP} / \mathrm{sHB}$ xenograft tumors by sucrose density gradient ultracentrifugation $(n=4$ tumors per condition) $(P<0.01)$. (B) Evidence for increased tyrosine phosphorylation of lipid raft proteins isolated from $\mathrm{LNCaP} / \mathrm{sHB}$ xenograft tumors by differential solubilization in Triton X-100 and OCG (38). OCGsoluble proteins were resolved by SDS-PAGE, transferred to nitrocellulose, and blotted with anti-phosphotyrosine antibody (right panel). Top panel: Quantitative evaluation by scanning densitometry of immunoblot shown on the bottom $(P<0.0005)$. MW, molecular weight.

in rafts (Figure 2D). We conclude from these experiments that the effects of simvastatin are substantially more evident on raft-resident Akt than on Akt in the nonraft membrane and that this suppressive effect can be reversed with cholesterol repletion.

Cholesterol regulates Akt signaling, but not apoptosis, in normal prostate epithelial cells. To determine the effect of lipid raft disruption on Akt signaling in a relevant normal cell type, we evaluated Akt phosphorylation in early-passage normal prostate epithelial cells (PrECs) in response to the cholesterol-binding agents filipin and 2 -hydroxypropyl- $\beta$-cyclodextrin, as well as simvastatin. As anticipated, EGF stimulated Akt phosphorylation in PrECs (Figure 3A); however, this effect was potently amplified by increasing membrane cholesterol levels (Figure 3A, lanes 1, 5, and 6). Filipin, cyclodextrin, and simvastatin inhibited EGF-induced Akt phosphorylation (Figure 3A, lanes 2-5). Filipin and cyclodextrin both inhibited the ability of cholesterol to potentiate EGF-dependent Akt phosphorylation (Figure 3A, lanes 7 and 8). Cholesterol repletion following filipin and cyclodextrin treatment restored Akt phosphorylation to levels that were comparable to those seen with EGF alone (Figure 3A, lanes 9 and 10). In the absence of EGF, cholesterol, used singly, modestly activated Akt (Figure 3, lane 11). These data indicate that plasma membrane cholesterol is a component of Akt pathway signaling in PrECs as it is in LNCaP cells.

To determine whether PrECs were susceptible to HMG-CoA reductase inhibitor-induced apoptosis, PrECs were treated for 24 hours with up to $100 \mu \mathrm{M}$ simvastatin. Apoptosis rates were not demonstrably affected by these treatments (Figure $3 \mathrm{~B}$ ). These observations are consistent with published findings describing the triggering of apoptosis in LNCaP cells with PI3K inhibitors under conditions where PrECs were unaffected (37).

Elevated circulating cholesterol alters tumor lipid rafts in vivo. An implication of the finding that the Akt survival function is regulated by cholesterol-rich microdomains is that membrane cholesterol is a mediator of tumor cell survival in vivo. To test this hypothesis, we carried out experiments in which tumor xenografts were created in SCID mice under normal conditions and under conditions where serum cholesterol was chronically elevated. Circulating cholesterol was raised by feeding with a hypercholesterolemic diet, an established method of raising serum cholesterol in rodents (40). We also attempted to lower cholesterol in vivo with simvastatin. However, treatment of SCID mice over a 4-week period with daily i.p. injections of simvastatin $(20 \mathrm{mg} / \mathrm{kg})$ did not lower cholesterol levels (not shown); this is consistent with previous reports that statin drugs at physiologically relevant doses do not lower serum lipids in mice, even under hyperlipidemic conditions (41-44).

After 4 weeks on the high-cholesterol regimen, total serum cholesterol concentrations were significantly elevated (Figure 4A). 
A Starved
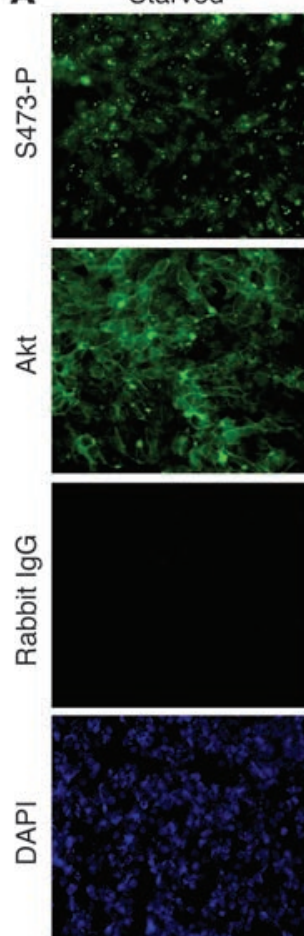

Pervanadate
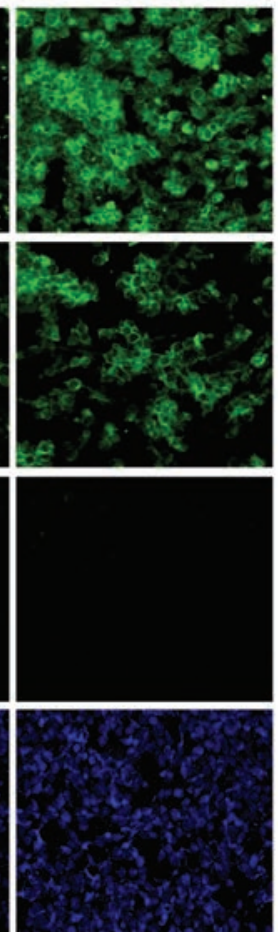

B

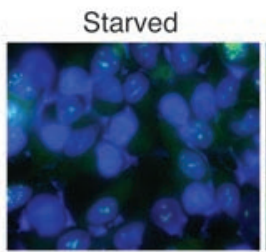

C

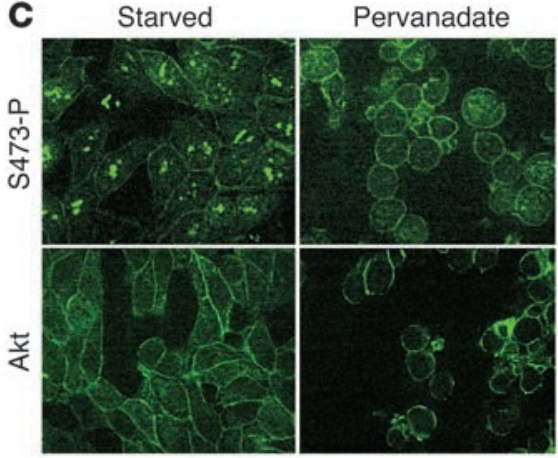

D

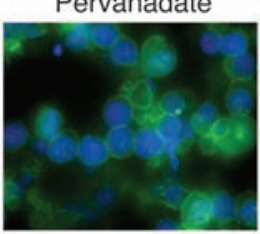

Pervanadate

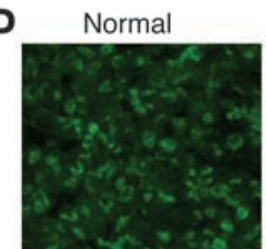

High cholesterol

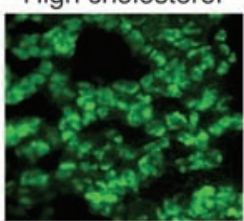

Intensity (INT/mm²) 0 100200300400500600700800

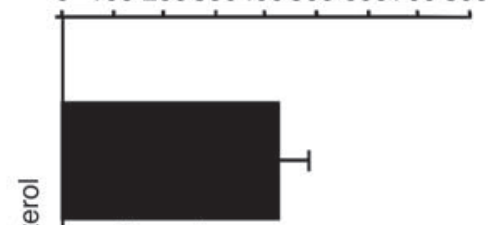

Normal

등

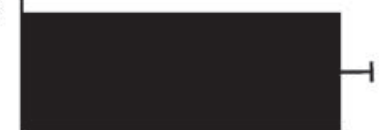

High

Figure 6

Increased Akt activation in xenograft tumors from mice with high circulating cholesterol. (A-C) Tests of S473-P antibody specificity for the experiment shown in $\mathbf{D}$. LNCaP cells were starved in serum-free medium at $37^{\circ} \mathrm{C}$ for 16 hours and then treated with $0.5 \mathrm{mM}$ pervanadate for 15 minutes at $37^{\circ} \mathrm{C}$. Original magnification: A, $\times 200$; B and C, $\times 600$. (D) Anti-phospho-Akt1 antibody was used to detect the status of Akt activation in $\mathrm{LNCaP} / \mathrm{sHB}$ xenograft tumors from normal and high-cholesterol animals with the immunofluorescence procedures used for $\mathbf{A}-\mathbf{C}$. Two representative images are shown (original magnification, $\times 400$ ). Optical intensities of the images were determined automatically with computer-controlled software ( $n=4$ in each group). The values shown are mean signal intensity (INT) per square millimeter \pm SD versus group $(P<0.001)$.

Tumor xenografts were created using LNCaP/sHB cells (45), an LNCaP subline engineered to constitutively secrete the processed form of the EGFR/ErbB1 activator heparin-binding EGF-like growth factor (HB-EGF). LNCaP/sHB cells efficiently form tumors in SCID mice (45). Tumor incidence 6 weeks after cell injection, and tumor volumes measured at 5 and 6 weeks after injection, were both significantly increased in the high-cholesterol group in comparison with the normal group (Figure 4, B-D).

We sought to determine whether lipid raft membranes isolated from $\mathrm{LNCaP} / \mathrm{sHB}$ xenograft tumors exhibited alterations attributable to the high-cholesterol regimen. Cholesterol content of lipid rafts isolated from tumor xenografts by sucrose gradient ultracentrifugation (as shown in Figure 2) was significantly elevated in the high-cholesterol group in comparison with the normal group (Figure 5A). This demonstrates that elevated circulating cholesterol increases the cholesterol content of lipid raft membranes in tumors. Lipid raft protein fractions were also isolated from xenografts by differential solubilization in Triton X-100 and OCG (38) in order to evaluate levels of protein phosphorylation on tyrosine residues. Tyrosine phosphorylation of lipid raft proteins was significantly increased in the high-cholesterol group (Figure 5B).

Increased Akt activation and decreased apoptosis in xenograft tumors exposed to high circulating cholesterol. To determine whether high circulating cholesterol alters cell survival within tumors, we analyzed $\mathrm{LNCaP} / \mathrm{sHB}$ tumors harvested from animals in the high-cholesterol and normal groups for Akt activation status and apoptotic frequency.
In order to perform this analysis we first confirmed that our antiphospho-Akt (S473-P) antibody was suitable to identify activated Akt by immunofluorescence microscopy. To test this, serum-starved LNCaP cells were treated with pervanadate, one of the most potent known Akt activators $(46,47)$, and Akt and phospho-Akt were localized by immunofluorescence (Figure 6A). As shown in the figure, staining with the anti-phospho-Akt antibody increased dramatically after pervanadate treatment. In addition, Akt was localized predominantly at the cell membrane, consistent with the literature on the effects on Akt activation of pervanadate and other agents (46-49) (Figure 6, A-C). Tissue sections from $\mathrm{LNCaP} / \mathrm{sHB}$ xenograft tumors taken from mice in normal and high-cholesterol cohorts were subsequently analyzed. Using the same staining protocol used for the cultured cells, we observed that Akt activation was significantly increased in tumors harvested from the high-cholesterol group (Figure 6D). Consistent with this result, the percentage of apoptotic cells in tumors obtained from the high-cholesterol group was significantly reduced in comparison with that in tumors obtained from the normal group (Figure 7), strongly suggesting a suppressive effect of elevated cholesterol on apoptotic signaling within the tumors.

\section{Discussion}

This study has provided evidence that cholesterol is a mediator of signal transduction processes relevant to PCa tumor cell survival and disease progression. We used 2 complementary approaches to study the possible effects of cholesterol targeting in PCa cells and 

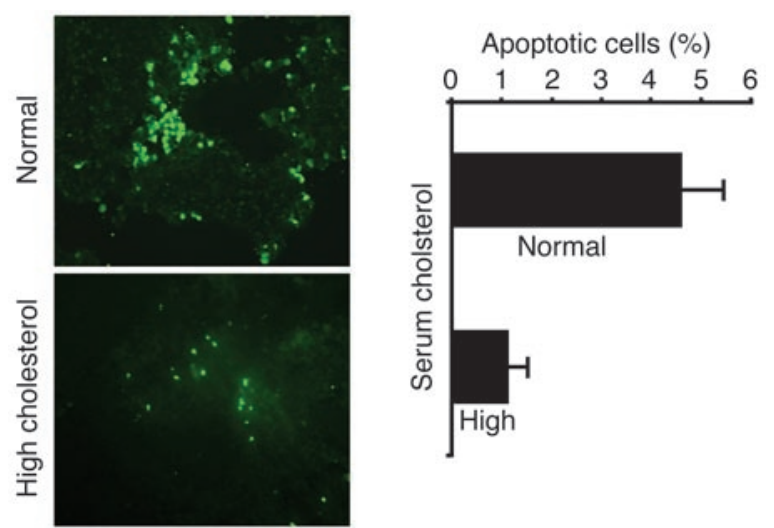

Figure 7

Reduced apoptosis in xenograft tumors from mice with high circulating cholesterol. Apoptosis rates in $\mathrm{LNCaP} / \mathrm{sHB}$ xenograft tumors from normal $(n=3)$ and high-cholesterol $(n=4)$ groups as evaluated by TUNEL (original magnification, $\times 200$ ). Fluorescence originates from condensed nuclei in apoptotic cells. The graph is presented as percent apoptotic cells (apoptotic cells/total cells) \pm SD versus group $(P<0.001)$.

tumors. First, the HMG-CoA reductase inhibitor simvastatin was used to determine whether inhibition of endogenous cholesterol biosynthesis in LNCaP human PCa cells is capable of altering cell survival and signal transduction through the Akt serine-threonine kinase and its downstream effectors. Simvastatin significantly decreased the cholesterol content of lipid rafts, inhibited Akt signaling, and stimulated apoptosis in LNCaP cells. Caspase-7 appeared to be a mediator of apoptosis, consistent with the pattern of caspase activation previously reported for lovastatininduced apoptosis in LNCaP cells (35). These effects are likely the result of alterations in membrane cholesterol, since they were all reversed by repletion of cell membranes with cholesterol. Evidence for a role for cholesterol in Akt signaling was also obtained using PrECs. Addition of cholesterol to cell membranes enhanced growth factor-activated Akt phosphorylation in PrECs. This effect was reversed by inhibition of cholesterol biosynthesis and by cholesterol-binding agents. Notably, the cholesterol-depleting drugs did not induce detectable apoptotic effects in the nontransformed cells as they did in LNCaP cells; this result is similar to published results on the effect of PI3K inhibitors (which inhibit Akt signaling) (37). These findings suggest that certain prostate cancers might be susceptible to cholesterol-targeted therapy, particularly in the case of tumors that become dependent on PI3K/Akt pathway signaling for cell survival (37).

The precise mechanism by which Akt isoforms become activated at the cell membrane is still poorly understood, although translocation to the plasma membrane is an important step in this process $(48,49)$. Consistent with our previous findings on EGFR (23), we found only a minority fraction of the membrane-proximal pool of Akt localized to rafts, and this pattern was unaltered by simvastatin treatment. Notably, however, raft-resident Akt was strongly inhibited by simvastatin within 4 hours after treatment, whereas Akt in the nonraft membrane/membrane-proximal cytosolic fraction was not inhibited during this time period. This effect was reversible with cholesterol repletion. This result strongly suggests that the lipid raft compartment is a dynamic site of Akt regulation by a cholesterol-sensitive process. Consistent with this interpretation, DNA-PK, a DNA-dependent protein kinase capable of phosphorylating Akt1 on one of the principal regulatory phosphorylation sites (S473), was recently shown to reside in lipid rafts $(50,51)$. Collectively, these observations indicate that Akt signaling is under the control of a cholesterol-dependent mechanism and that the essential cell survival function of this pathway in tumor cells is compromised by lowering of membrane cholesterol levels and/or alteration of lipid raft structure.

As a second approach to determining the role of raft-resident cholesterol in tumor cell survival, we created LNCaP/sHB xenografts in SCID mice and tested the effect of elevated circulating cholesterol on tumor growth, lipid raft composition, Akt phosphorylation, and apoptosis in vivo. Tumor take and volume, cholesterol content, and levels of tyrosine phosphorylation of proteins in tumor lipid rafts were all increased under the high-cholesterol regimen. Consistent with the assertion that the effects on tumor lipid rafts are functionally significant, Akt phosphorylation at a critical activation site was increased and apoptosis was suppressed in the xenograft tumors obtained from the high-cholesterol cohort. In concert with the simvastatin experiments, these findings provide substantial evidence that cholesterol content of tumor cell membranes is a prominent mediator of tumor cell survival mechanisms that operate in vivo.

Simvastatin and other statin drugs affect the synthesis of other products of the mevalonate pathway, such as farnesyl pyrophosphate and geranyl pyrophosphate, which are also used in the posttranslational modification of a number of signaling proteins, such as Ras and Rho GTPases. Statin drugs have been shown to inhibit properties associated with tumor progression, such as cell proliferation, invasion through an ECM barrier, and the expression of genes upregulated in aggressive cancers. Some of these effects have been attributed to inhibition of isoprenoid synthesis $(52,53)$. Although some antitumor effects of these compounds are likely to involve inhibition of pathways independent of lipid raft signaling, our study, using a variety of approaches, suggests that cholesterol resident in rafts is responsible for many of the effects we report here. This is because (a) inhibition of endogenous cholesterol synthesis, as well as the elevation of circulating cholesterol in vivo, substantially altered the composition of tumor cell rafts as well as cell signaling events dependent on intact raft microdomains; (b) we mimicked the apoptotic effect of cholesterol-binding compounds in PI3K/Akt-dependent cells by inhibiting endogenous cholesterol synthesis, and this was reversed by reconstitution of cholesterol-depleted cell membranes with cholesterol; and (c) we accentuated Akt signaling in vitro and in vivo by increasing cholesterol levels in rafts using multiple approaches. Because these findings link a discrete cell survival pathway (PI3K/Akt) directly to raft-resident cholesterol, we believe it is highly unlikely that our results can be explained by a model that relies predominantly on effects of inhibition of isoprenoid synthesis.

Hedgehog (Hh) pathway signaling components, such as the secreted protein sonic hedgehog (Shh), the Hh receptor Patched (Ptc), and the downstream effector Gli, have recently been implicated in PCa cell proliferation and clinical progression of the disease by several groups (54-56). Significantly, Hh family members are posttranslationally modified by cholesterol addition during processing to the active form. Hh and Ptc, and the positive regulator Smoothened (Smo), have been reported to localize to lipid rafts, and the Hh receptor complex can be altered by depletion of membrane cholesterol (57). Thus, in addition to PI3K/Akt, the 
Hh pathway may represent another signaling mechanism relevant to clinical PCa that is potentially modifiable therapeutically by targeting of cholesterol.

Our observations may also be relevant to published epidemiological relationships between PCa aggressiveness and a Western diet $(18,19)$. Epidemiological studies $(19,58,59)$, and experimental models of dietary factors $(60,61)$, have shown that diet is potentially a promising means of controlling rates of PCa progression (20). In addition, recent studies of the long-term effects of statin therapy have also provided evidence that cholesterol lowering may reduce cancer incidence $(32,33)$. Our findings provide a mechanism that may underlie some of these observations. We and others have shown that lipid raft membrane microdomains are functionally modulated by increases and decreases in cholesterol content $(21,23,62)$. The present study provides direct evidence that alterations in circulating cholesterol levels, or endogenous cholesterol synthesis in tumor cells, are capable of altering the composition of - and information transfer through - an important signaling platform in the tumor cell membrane. Inactivation of a negative regulator of the Akt pathway, the PTEN lipid phosphatase, has been implicated in brain, prostate, and other solid tumors (27). Genetic alteration at the pten locus, leading to functional loss of the protein, is common in some cancers and results in PI3K/Akt upregulation (30). PTEN inactivation may occur late in tumor progression, including in PCa (28). Our present findings with the LNCaP model, which is PTEN-null, suggest that pharmacologic or dietary modulation of raft-dependent cell survival signaling may be possible even in aggressive tumors that arise late in cancer progression. Our group recently reported that lipid raft microdomains in LNCaP cells are capable of processing an IL-6/STAT-3-mediated signal, which is independent of the Akt pathway but which also accentuates tumor cell properties associated with a more aggressive cancer phenotype (62). Taken together, these observations support a role for lipid raft-mediated signaling events as prominent contributors to progression mechanisms relevant to PCa and possibly to other solid tumors.

Because we have used caveolin-negative cells for the present study (62), our findings also demonstrate that cholesterol-dependent changes in tumor cell rafts are capable of altering signal transduction mechanisms independently of caveolins, which are well-known signaling mediators. Caveolin expression is frequently downregulated with malignant transformation (63); thus, our results may be applicable to tumor cell signaling mechanisms more generally since they are not dependent on the presence of caveolin in the raft membrane fraction.

Finally, an important implication of our findings that membrane cholesterol is a mediator of PCa tumor cell survival is that HMG-CoA reductase inhibitors, which are widely used to lower circulating cholesterol in management of cardiovascular disease, may be of use in chemoprevention or cancer therapy, possibly in combination with other modalities (64). These findings also suggest that the lipid raft microdomain is a promising subcellular location for the identification of novel molecular targets involved in cholesterol-dependent tumor progression mechanisms.

\section{Methods}

Cell culture. The human PCa cell line LNCaP (American Type Culture Collection), which does not express detectable levels of caveolin (23) or the PTEN phosphatase (30), was cultured according to the company's instructions. Early-passage (passages 3-5) normal human prostate epithelial cells (PrECs; strain 4428; Cambrex Corp.) were expanded in PrEGM medium (Cambrex Corp.) according to the company's specifications. LNCaP/sHB cells (45) were cultured in $10 \% \mathrm{FBS} / \mathrm{RPMI} 1640$ with $200 \mu \mathrm{g} / \mathrm{ml}$ hygromycin. All cells were cultured in a humidified atmosphere with $5 \% \mathrm{CO}_{2}$ at $37^{\circ} \mathrm{C}$.

Antibodies and reagents. The following $\mathrm{mAbs}$ and polyclonal antibodies (pAbs) were used: anti-EGFR pAb and anti-G $\mathrm{G}_{\mathrm{i} \alpha 2}$ pAb (Santa Cruz Biotechnology Inc.); anti-flotillin-2/epidermal surface antigen $\mathrm{mAb}$ (Transduction Laboratories); anti-Akt1 pAb, anti-phospho-Akt (Ser473) pAb, anti-phospho-Akt (Ser473, immunohistochemistry-specific) pAb, anti-phospho-Akt (Thr308) pAb, cleaved caspase-7 (Asp198) pAb, and anti-phospho-glycogen synthase kinase $3 \alpha / \beta$ (anti-phospho-GSK3 $\alpha / \beta$ ) pAb (Cell Signaling Technology Inc.); anti- $\beta$-actin mAb (Sigma-Aldrich); anti-cyclin A pAb (BIOMOL Research Laboratories Inc.). Human recombinant EGF was from R\&D Systems Inc. GSK3 fusion protein was from Cell Signaling Technology Inc. Filipin-III, cholesterol, 2-hydroxypropyl$\beta$-cyclodextrin, OCG, water-soluble cholesterol, and the Infinity cholesterol-determination reagent were from Sigma-Aldrich. Simvastatin was obtained from Merck and Co.

DNA fragmentation and TUNEL assays. A quantitative sandwich ELISA to measure apoptosis was performed according to the manufacturer's specifications (Cell Death Detection ELISA; Roche Diagnostics Corp.) and as described previously (23). To identify apoptosis in tumor sections, the TUNEL method was applied, using the In Situ Cell Death Detection Kit (Roche Diagnostics Corp.). Briefly, frozen sections were fixed in $4 \%$ paraformaldehyde and permeabilized, and DNA was labeled with fluorescein using the TUNEL reaction mix. Nuclei were counterstained with DAPI. Apoptotic cells were visualized under an Olympus Corp. fluorescence microscope equipped with a computer-controlled digital camera. The ratio of apoptotic cells and total cells was counted in 3 random views.

Whole-cell lysate preparation and immunoblotting. Cells were solubilized with $50 \mathrm{mM}$ Tris-HCl (pH 7.4), 1\% NP-40, 0.25\% Na deoxycholate, $150 \mathrm{mM}$ $\mathrm{NaCl}, 1 \mathrm{mM} \mathrm{NaF}, 1 \mathrm{mM}$ orthovanadate, and Complete protease inhibitor cocktail (Roche Diagnostics Corp.). After 30 minutes of incubation on ice, lysates were clarified by centrifugation $(10,000 \mathrm{~g})$ for 15 minutes at $4^{\circ} \mathrm{C}$ and supernatants were collected. Protein concentrations were determined using the Bio-Rad Laboratories DC protein assay kit, and equal amounts were subjected to SDS/linear gradient PAGE following solubilization in Laemmli sample buffer. Gel-resolved proteins were subsequently electrotransferred to nitrocellulose membranes, which were blocked with $5 \%$ nonfat milk, incubated with various primary antibodies used at 1:1,000 dilutions (except anti-EGFR pAb and anti- $\beta$-actin mAb, used at 1:5,000), and developed with HRP-conjugated secondary antibodies using the SuperSignal chemiluminescence system (Pierce Biotechnology Inc.).

Isolation of cholesterol-enriched membranes. Lipid raft membranes were isolated using 2 methods: (a) flotation in sucrose gradients and (b) differential extraction with Triton X-100 and OCG detergents. The sucrose gradient method was performed essentially as described previously (39). Following centrifugation, gradients were portioned into $1-\mathrm{ml}$ fractions. The pellet on the bottom of the tube was resuspended in $1 \mathrm{ml} 20 \mathrm{mM} \mathrm{KCl}$. The protein concentration in each fraction was determined with the DC protein assay kit. Raft fractions were also isolated from xenograft tumors and LNCaP cells by successive detergent extraction essentially as described previously $(23,38)$. Briefly, xenograft tumors (which were stored at $-80^{\circ} \mathrm{C}$ ) were chopped and homogenized in ice-cold PBS containing protease inhibitors, and tumor cells were collected by rapid centrifugation at $4{ }^{\circ} \mathrm{C}$. Cell lysates were prepared in buffer A [ $25 \mathrm{mM} 2$-( $N$-morpholino)-ethanesulfonic acid, $150 \mathrm{mM} \mathrm{NaCl}, \mathrm{pH} 6.5]$, and an equal volume of the same buffer with $2 \%$ Triton $\mathrm{X}-100,2 \mathrm{mM} \mathrm{Na}_{3} \mathrm{VO}_{4}$, and $2 \mathrm{mM}$ PMSF was added. After 30 minutes of incubation, lysates were centrifuged and supernatants (containing the Triton-soluble fraction) were removed. Insoluble pellets were resuspended 
with buffer B (1\% Triton X-100, $10 \mathrm{mM}$ Tris-Cl [pH 7.6], $500 \mathrm{mM} \mathrm{NaCl}$, $2 \mathrm{mM} \mathrm{Na}_{3} \mathrm{VO}_{4}, 60 \mathrm{mM} \beta$-octylglucoside [OCG], and $1 \mathrm{mM}$ PMSF) for 30 minutes on ice. Triton-insoluble and OCG-soluble supernatants were collected after 20 minutes of centrifugation at $15,000 \mathrm{~g}$.

Lipid analyses. Aliquots $(350 \mu \mathrm{l})$ of each sucrose density gradient fraction were extracted in chloroform/methanol/ $\mathrm{HCl}$ as described previously (65), and the cholesterol concentration was determined using the Infinity reagent.

Immunofluorescence labeling. Cells grown on chamber slides (Nalge Nunc International) were rinsed once with cold PBS, fixed in $-20^{\circ} \mathrm{C}$ methanol for 5 minutes, and kept at $-80^{\circ} \mathrm{C}$ until use. Xenograft tumors were dissected, immediately washed 3-5 times in cold PBS, and embedded in OCT compound (Tissue-Tek; Sakura Finetek USA Inc.). Cryostat-sectioned 5 - $\mu \mathrm{m}$ slices were mounted on Superfrost/Plus microscope slides (Fisher Scientific International Co.) and kept at $-80^{\circ} \mathrm{C}$ until use. For immunostaining of tissues, slides were equilibrated at room temperature until dry, then immersed in $-20^{\circ} \mathrm{C}$ methanol for 5 minutes. After 5 -minute washes ( 3 times) in Tris-buffered saline (TBS), slides were blocked with $3 \% \mathrm{BSA}$ in TBS $/ 0.1 \%$ Triton for 30 minutes. The immunohistochemistryspecific anti-phospho-Akt (Ser473) antibody was used at 1:100 dilution in $3 \% \mathrm{BSA} / \mathrm{TBS} /$ Triton $\mathrm{X}-100$ at $4^{\circ} \mathrm{C}$ overnight. After washing, the secondary FITC-labeled anti-rabbit IgG was added for 45 minutes. Slides were mounted with VECTASHIELD with DAPI (Vector Laboratories Inc.) and were visualized by fluorescence microscopy. Images of each sample were randomly captured 3 times with the same set of optical parameters. All of the images were converted into gray scale, $8-15$ cells per image were randomly selected, and the intensity per square millimeter was measured with imaging software (Quantity One; Bio-Rad Laboratories).

Akt kinase assay. Akt kinase activity was measured using an assay kit (Cell Signaling Technology Inc.) essentially according to the manufacturer's instructions. Briefly, cells were rinsed with ice-cold PBS, and cell lysis buffer (containing $1 \mathrm{mM} \mathrm{PMSF}$ ) was added and incubated on ice for $10 \mathrm{~min}$ utes. The cells were scraped and centrifuged at $4^{\circ} \mathrm{C}$ for 10 minutes. Two hundred microliters of lysate and $20 \mu \mathrm{l}$ of immobilized Akt antibody slurry were mixed and incubated with gentle rocking at $4^{\circ} \mathrm{C}$ for $2-3$ hours. After centrifugation, pellets were washed twice consecutively in lysis buffer and kinase buffer, then resuspended in $40 \mu \mathrm{l}$ kinase buffer supplemented with $200 \mu \mathrm{M}$ ATP and $1 \mu \mathrm{g}$ GSK3 fusion protein. After incubation for $30 \mathrm{~min}-$ utes at $30^{\circ} \mathrm{C}$, the reaction was terminated in SDS sample buffer. Samples were analyzed by immunoblot using an anti-phospho-GSK3 $\alpha / \beta$ antibody.
Preparation of activated simvastatin. Activated simvastatin was prepared as described previously (66) and adjusted to a final concentration of $10 \mathrm{mM}$ with sterile PBS (pH 7.2).

Tumor xenografts. Two-month-old male SCID mice were purchased from the Massachusetts General Hospital Animal Facility and divided into 2 groups. One group (Normal) was fed normal mouse chow. A second group (High cholesterol) was fed a hypercholesteremic diet (Paigen method, Teklad diet number 88051; Harlan Teklad). Xenograft tumors were initiated by cell injection after 1 month on either the normal or the high-cholesterol diet regimen with $2 \times 10^{6} \mathrm{LNCaP} / \mathrm{sHB}$ cells per implant site using $150 \mu \mathrm{l}$ Matrigel (BD Biosciences) as the vehicle. Animals were sacrificed 6 weeks after tumor cell implantation, and tumors were removed, weighed, and split into 2 parts, one fixed in $10 \%$ buffered formalin and embedded in paraffin for histological analysis, and the other snap-frozen in liquid nitrogen and stored at $-80^{\circ} \mathrm{C}$. Serum cholesterol was measured in venous blood obtained by tail bleed. All animal experiments were in accordance with accepted standards of humane animal care and with the approval of the Institutional Animal Care and Use Committee, Children's Hospital Boston.

\section{Acknowledgments}

This study was supported by NIH and Department of Defense research grants (R37 DK47556, P50 DK65298, and DAMD1703-2-0033; to M.R. Freeman) and NIH grant R01 CA101046 (to K.R. Solomon). L. Zhuang, J. Kim, and R.M. Adam are American Foundation for Urologic Disease Research Scholars. We thank Carl Schaffner for helpful discussions, Fanglei You for help with sucrose gradients, Paul Guthrie for assistance with figure preparation, and Jessica Wagner for assistance with microscopic imaging.

Received for publication September 2, 2003, and accepted in revised form February 1, 2005.

Address correspondence to: Michael R. Freeman, John F. Enders Research Laboratories, Suite 1161, Children's Hospital Boston, 300 Longwood Avenue, Boston, Massachusetts 02115, USA. Phone: (617) 355-6054; Fax: (617) 730-0238; E-mail: michael. freeman@childrens.harvard.edu.

Liyan Zhuang and Jayoung Kim contributed equally to this work.
1. Pike, L.J. 2003. Lipid rafts: bringing order to chaos. J. Lipid Res. 44:655-667.

2. Deurs, B., Roepstorff, K., Hommelgaard, A.M., and Sandvig, K. 2003. Caveolae: anchored, multifunctional platforms in the lipid ocean. Trends Cell Biol. 13:92-100

3. Drab, M., et al. 2001. Loss of caveolae, vascular dysfunction, and pulmonary defects in caveolin-1 gene-disrupted mice. Science. 293:2449-2452.

4. Park, D.S., et al. 2002. Caveolin-1/3 double-knockout mice are viable, but lack both muscle and nonmuscle caveolae, and develop a severe cardiomyopathic phenotype. Am. J. Pathol. 160:2207-2217.

5. Liu, P., Rudick, M., and Anderson, R.G. 2002. Multiple functions of caveolin-1. J. Biol. Chem. 277:41295-41298.

6. Edidin, M. 2001. Membrane cholesterol, protein phosphorylation, and lipid rafts. Sci. STKE. 2001:PE1.

7. Yang, G., Truong, L.D., Wheeler, T.M., and Thompson, T.C. 1999. Caveolin-1 expression in clinically confined human prostate cancer: a novel prognostic marker. Cancer Res. 59:5719-5723.

8. Yang, G., Addai, J., Ittmann, M., Wheeler, T.M., and Thompson, T.C. 2000. Elevated caveolin-1 levels in African-American versus white-American prostate cancer. Clin. Cancer Res. 6:3430-3433.

9. Suzuoki, M., et al. 2002. Impact of caveolin-1 expression on prognosis of pancreatic ductal adenocarcinoma. Br. J. Cancer. 87:1140-1144.

10. Kato, K., et al. 2002. Overexpression of caveolin-1 in esophageal squamous cell carcinoma correlates with lymph node metastasis and pathologic stage. Cancer. 94:929-933.

11. Li, L., et al. 2001. Caveolin-1 mediates testosteronestimulated survival/clonal growth and promotes metastatic activities in prostate cancer cells. Cancer Res. 61:4386-4392.

12. Razandi, M., et al. 2003. Identification of a structural determinant necessary for the localization and function of estrogen receptor alpha at the plasma membrane. Mol. Cell. Biol. 23:1633-1646.

13. Lu, M.L., Schneider, M.C., Zheng, Y., Zhang, X., and Richie, J.P. 2001. Caveolin-1 interacts with androgen receptor. A positive modulator of androgen receptor mediated transactivation. J. Biol. Chem. 276:13442-13451.

14. Li, L., Ren, C.H., Tahir, S.A., Ren, C., and Thompson, T.C. 2003. Caveolin-1 maintains activated Akt in prostate cancer cells through scaffolding domain binding site interactions with and inhibition of serine/threonine protein phosphatases PP1 and PP2A. Mol. Cell. Biol. 23:9389-9404.

15. Li, S., Couet, J., and Lisanti, M.P. 1996. Src tyrosine kinases, Galpha subunits, and H-Ras share a common membrane-anchored scaffolding protein, caveolin. Caveolin binding negatively regulates the auto-activation of Src tyrosine kinases. J. Biol. Chem. 271:29182-29190.

16. Engelman, J.A., et al. 1998. Reciprocal regulation of neu tyrosine kinase activity and caveolin-1 protein expression in vitro and in vivo. Implications for human breast cancer. J. Biol. Chem. 273:20448-20455.

17. Williams, T.M., et al. 2003. Loss of caveolin-1 gene expression accelerates the development of dysplastic mammary lesions in tumor-prone transgenic mice. Mol. Biol. Cell. 14:1027-1042.

18. Coffey, D.S. 2001. Similarities of prostate and breast cancer: evolution, diet, and estrogens. Urology. 57:31-38.

19. Michaud, D.S., et al. 2001. A prospective study on intake of animal products and risk of prostate cancer. Cancer Causes Control. 12:557-567.

20. Freeman, M.R., and Solomon, K.R. 2004. Cholesterol and prostate cancer. J. Cell. Biochem. 91:54-69.

21. Ushio-Fukai, M., et al. 2001. Cholesterol depletion 
inhibits epidermal growth factor receptor transactivation by angiotensin II in vascular smooth muscle cells: role of cholesterol-rich microdomains and focal adhesions in angiotensin II signaling. J. Biol. Chem. 276:48269-48275

22. Sehgal, P.B., Guo, G.G., Shah, M., Kumar, V., and Patel, K. 2002. Cytokine signaling: STATS in plasma membrane rafts. J. Biol. Chem. 277:12067-12074.

23. Zhuang, L., Lin, J., Lu, M.L., Solomon, K.R., and Freeman, M.R. 2002. Cholesterol-rich lipid rafts mediate akt-regulated survival in prostate cancer cells. Cancer Res. 62:2227-2231.

24. Li, Y., Cam, J., and Bu, G. 2001. Low-density lipoprotein receptor family: endocytosis and signal transduction. Mol. Neurobiol. 23:53-67.

25. Hentosh, P., Yuh, S.H., Elson, C.E., and Peffley, D.M. 2001. Sterol-independent regulation of 3-hydroxy3-methylglutaryl coenzyme A reductase in tumor cells. Mol. Carcinog. 32:154-166.

26. Chen, Y., and Hughes-Fulford, M. 2001. Human prostate cancer cells lack feedback regulation of low-density lipoprotein receptor and its regulator, SREBP2. Int. J. Cancer. 91:41-45.

27. Vivanco, I., and Sawyers, C.L. 2002. The phosphatidylinositol 3-kinase AKT pathway in human cancer. Nat. Rev. Cancer. 2:489-501.

28. Halvorsen, O.J., Haukaas, S.A., and Akslen, L.A. 2003. Combined loss of PTEN and p27 expression is associated with tumor cell proliferation by Ki-67 and increased risk of recurrent disease in localized prostate cancer. Clin. Cancer Res. 9:1474-1479.

29. McMenamin, M.E., et al. 1999. Loss of PTEN expression in paraffin-embedded primary prostate cancer correlates with high Gleason score and advanced stage. Cancer Res. 59:4291-4296.

30. Wu, X., Senechal, K., Neshat, M.S., Whang, Y.E., and Sawyers, C.L. 1998. The PTEN/MMAC1 tumor suppressor phosphatase functions as a negative regulator of the phosphoinositide 3-kinase/Akt pathway. Proc. Natl. Acad. Sci. U. S. A. 95:15587-15591.

31. Kaye, J.A., Meier, C.R., Walker, A.M., and Jick, H. 2002. Statin use, hyperlipidaemia, and the risk of breast cancer. Br. J. Cancer. 86:1436-1439.

32. Pedersen, T.R., et al. 2000. Follow-up study of patients randomized in the Scandinavian simvastatin survival study (4S) of cholesterol lowering. Am. J. Cardiol. 86:257-262.

33. Graaf, M.R., Beiderbeck, A.B., Egberts, A.C., Richel, D.J., and Guchelaar, H.J. 2004. The risk of cancer in users of statins. J. Clin. Oncol. 22:2388-2394.

34. Hess, D.C., and Fagan, S.C. 2001. Pharmacology and clinical experience with simvastatin. Expert Opin. Pharmacother. 2:153-163.

35. Marcelli, M., et al. 1998. Caspase-7 is activated during lovastatin-induced apoptosis of the prostate cancer cell line LNCaP. Cancer Res. 58:76-83.

36. Murillo, H., Huang, H., Schmidt, L.J., Smith, D.I., and Tindall, D.J. 2001. Role of PI3K signaling in survival and progression of $\mathrm{LNCaP}$ prostate cancer cells to the androgen refractory state. Endocrinology. 142:4795-4805.

37. Lin, J., Adam, R.M., Santiestevan, E., and Freeman,
M.R. 1999. The phosphatidylinositol 3'-kinase pathway is a dominant growth factor-activated cell survival pathway in $\mathrm{LNCaP}$ human prostate carcinoma cells. Cancer Res. 59:2891-2897.

38. Solomon, K.R., Mallory, M.A., and Finberg, R.W. 1998. Determination of the non-ionic detergent insolubility and phosphoprotein associations of glycosylphosphatidylinositol-anchored proteins expressed on T cells. Biochem. J. 334:325-333.

39. Solomon, K.R., Adolphson, L.D., Wank, D.A., McHugh, K.P., and Hauschka, P.V. 2000. Caveolae in human and murine osteoblasts. J. Bone Miner. Res. 15:2391-2401.

40. Joyce, C.W., et al. 2002. The ATP binding cassette transporter $\mathrm{A} 1$ (ABCA1) modulates the development of aortic atherosclerosis in C57BL/6 and apoE-knockout mice. Proc. Natl. Acad. Sci. U. S. A. 99:407-412.

41. Chen, Z., et al. 2002. Simvastatin reduces neointimal thickening in low-density lipoprotein receptor-deficient mice after experimental angioplasty without changing plasma lipids. Circulation. 106:20-23.

42. Bea, F., et al. 2002. Simvastatin promotes atherosclerotic plaque stability in apoE-deficient mice independently of lipid lowering. Arterioscler. Thromb. Vasc. Biol. 22:1832-1837.

43. Sparrow, C.P., et al. 2001. Simvastatin has antiinflammatory and antiatherosclerotic activities independent of plasma cholesterol lowering. Arterioscler. Thromb. Vasc. Biol. 21:115-121.

44. Choudhury, R.P., et al. 2004. Effects of simvastatin on plasma lipoproteins and response to arterial injury in wild-type and apolipoprotein-E-deficient mice. J. Vasc. Res. 41:75-83.

45. Adam, R.M., et al. 2002. Heparin-binding epidermal growth factor-like growth factor stimulates androgen-independent prostate tumor growth and antagonizes androgen receptor function. Endocrinology. 143:4599-4608

46. Andjelkovic, M., et al. 1996. Activation and phosphorylation of a pleckstrin homology domain containing protein kinase (RAC-PK/PKB) promoted by serum and protein phosphatase inhibitors. Proc. Natl. Acad. Sci. U. S. A. 93:5699-5704.

47. Conus, N.M., Hannan, K.M., Cristiano, B.E., Hemmings, B.A., and Pearson, R.B. 2002. Direct identification of tyrosine 474 as a regulatory phosphorylation site for the Akt protein kinase. J. Biol. Chem. 277:38021-38028.

48. Andjelkovic, M., et al. 1997. Role of translocation in the activation and function of protein kinase $\mathrm{B}$. J. Biol. Chem. 272:31515-31524.

49. Scheid, M.P., Marignani, P.A., and Woodgett, J.R. 2002. Multiple phosphoinositide 3-kinase-dependent steps in activation of protein kinase B. Mol. Cell. Biol. 22:6247-6260

50. Hill, M.M., Feng, J., and Hemmings, B.A. 2002. Identification of a plasma membrane Raft-associated PKB Ser473 kinase activity that is distinct from ILK and PDK1. Curr. Biol. 12:1251-1255.

51. Feng, J., Park, J., Cron, P., Hess, D., and Hemmings, B.A. 2004. Identification of a PKB/Akt hydropho- bic motif Ser-473 kinase as DNA-dependent protein kinase. J. Biol. Chem. 279:41189-41196.

52. Denoyelle, C., et al. 2001. Cerivastatin, an inhibitor of HMG-CoA reductase, inhibits the signaling pathways involved in the invasiveness and metastatic properties of highly invasive breast cancer cell lines: an in vitro study. Carcinogenesis. 22:1139-1148

53. Denoyelle, C., et al. 2003. Molecular mechanism of the anti-cancer activity of cerivastatin, an inhibitor of HMG-CoA reductase, on aggressive human breast cancer cells. Cell. Signal. 15:327-338.

54. Karhadkar, S.S., et al. 2004. Hedgehog signalling in prostate regeneration, neoplasia and metastasis. Nature. 431:707-712.

55. Sanchez, P., et al. 2004. Inhibition of prostate cancer proliferation by interference with SONIC HEDGEHOG-GLI1 signaling. Proc. Natl. Acad. Sci. U. S. A. 101:12561-12566.

56. Fan, L., et al. 2004. Hedgehog signaling promotes prostate xenograft tumor growth. Endocrinology. 145:3961-3970

57. Karpen, H.E., et al. 2001. The sonic hedgehog receptor patched associates with caveolin- 1 in cholesterol-rich microdomains of the plasma membrane. J. Biol. Chem. 276:19503-19511.

58. Hsieh, L.J., et al. 2003. Association of energy intake with prostate cancer in a long-term aging study: Baltimore Longitudinal Study of Aging (United States). Urology. 61:297-301

59. Giovannucci, E., Rimm, E.B., Liu, Y., Stampfer, M.J., and Willett, W.C. 2002. A prospective study of tomato products, lycopene, and prostate cancer risk. J. Natl. Cancer Inst. 94:391-398.

60. Ngo, T.H., Barnard, R.J., Tymchuk, C.N., Cohen, P., and Aronson, W.J. 2002. Effect of diet and exercise on serum insulin, IGF-I, and IGFBP-1 levels and growth of LNCaP cells in vitro (United States). Cancer Causes Control. 13:929-935.

61. Zhou, J.R., et al. 2002. Inhibition of orthotopic growth and metastasis of androgen-sensitive human prostate tumors in mice by bioactive soybean components. Prostate. 53:143-153.

62. Kim, J., Adam, R.M., Solomon, K.R., and Freeman, M.R. 2004. Involvement of cholesterol-rich lipid rafts in interleukin-6-induced neuroendocrine differentiation of $\mathrm{LNCaP}$ prostate cancer cells. Endocrinology. 145:613-619.

63. Wiechen, K., et al. 2001. Caveolin-1 is down-regulated in human ovarian carcinoma and acts as a candidate tumor suppressor gene. Am. J. Pathol. 159:1635-1643.

64. Chan, K.K., Oza, A.M., and Siu, L.L. 2003. The statins as anticancer agents. Clin. Cancer Res. 9:10-19.

65. Hope, H.R., and Pike, L.J. 1996. Phosphoinositides and phosphoinositide-utilizing enzymes in detergent-insoluble lipid domains. Mol. Biol. Cell. 7:843-851.

66. Bassa, B.V., Roh, D.D., Vaziri, N.D., Kirschenbaum, M.A., and Kamanna, V.S. 1999. Lysophosphatidylcholine activates mesangial cell PKC and MAP kinase by PLCgamma-1 and tyrosine kinase-Ras pathways. Am. J. Physiol. 277:F328-F337. 